\title{
User Experience in Digital Games
}

\author{
Jari Takatalo*, Jukka Häkkinen+, Jyrki Kaistinen* \& Göte Nyman* \\ ${ }^{*}$ University of Helsinki, ${ }^{+}$Nokia Research Centre \\ Finland
}

\section{Introduction}

This chapter concentrates on the psychological analysis of the user experience (UX). We present three different psychological frameworks that have been used in the study of complex UX environments. They have been widely applied in different game contexts studied by the PDL (Psychology of Digital Life) research group at the University of Helsinki. The frameworks work their way from very general and theoretical aspects towards more specific and empirically validated model of the UX in games. Both theoretical and methodological issues are presented, including the empirical data collected $(n=2200)$ and the directional results that demonstrate how the psychological UX framework works in practice. Some other technology environments are also considered within the fundamental psychological concepts that all these frameworks share, that is, cognitions, emotions and motivations. It is shown, how basic psychology can be applied in order to understand the rich variety of human experiences. There are profound reasons to study games. They provide interactive entertainment for millions of users around the world. Economically they have exceeded traditional media, such as movies and music. Game companies have become forerunners of the software industry, guiding the future of the whole field and having impact also on hardware development. Gaming technology will be applied in numerous other areas as socially interactive virtual worlds (e.g., $2^{\text {nd }}$ Life) have already shown. New generations familiar with being and interacting in virtual environments are born. The daily activities of these citizens are shifting towards the world wide virtual world. This change has made games and virtual worlds also true topics in cultural discussions. Since games are played to get experiences, they are hard to study and understand with traditional usability methods that are typically applied in the field of human-computer interaction (HCI). This will be problematic when the future user interfaces evolve towards those used in games today. Thus, more holistic approaches to understand and evaluate the inner worlds of the users and their complex functionality in numerous technological contexts are required. When the holistic nature of the human experience is studied systematically with methodologically solid approaches, psychological understanding of the human experience in such environments increases and benefits the designing of value and UX for these environments. 


\section{User Experience}

The study of UX arises from the need to understand the complexity of HCI. Conventionally in the field of $\mathrm{HCI}$, applications are evaluated by task- and work-related usability metrics (Hassenzahl \& Tractinsky, 2006). However, concentrating on external behavior, such as, cognitive efficiency and objective measures of bottom-up processes does not reach the relevant psychological phenomena that technological development has brought to people. Computers have moved from offices to homes, telephones have been shrunk to our pockets and demanding customers want experiences in addition to efficiency. Bottom-up usability issues remain relevant but a usable gadget needs to feel good, look smart, sound personal, and bring some added color to its user's inner life. In order to study and evaluate such deep psychological phenomena, a top-down approach to user psychology is needed. There is a simple reason for this: there is no well-defined bottom-up theory of human experience that would substantially contribute to the understanding of complex behavioral contexts, such as playing digital games.

The field of UX research is young and it still faces problems, such as incoherent concepts and lack of empirical research (Hassenzahl \& Tractinsky, 2006). Many of the studies are based on authors and designers personal experiences in the field and often the user's point of view is neglected (Fabricatore et al., 2002). However, there are also serious attempts towards consensual definition of UX (e.g., UXSIG, http://www.cost294.org). In these approaches, many essential psychological components are included (e.g., feeling, satisfaction, need, mood, motivation). However, many definitions would do better if they were more clearly aimed at describing what mental compartments are included into analysis and what experiential attributes are evaluated. This is a demanding task. It makes little sense to create lists of numerous mental ingredients that neglect the well established psychological research on human experience that offers scientifically validated, theoretical and empirical material for these purposes. Also in most of the UX definitions a product, service, event, design or system is referred as the object of the interaction responsible for UX. However, each of these cases has its own nature that should be regarded, in order to understand UX.

Naturally, UX in digital games and cellular phones is quite different. The past experience of the user and the context of use bring in variables that are both general and specific to the context. If we have a clear understanding of the dimensions and attributes of these experiences their measurement becomes easier. If we want to understand how two persons experience a red star, for example, it could be quite difficult to assess or even compare these two experiences without an idea of what we want to measure. With a general enough approach we can get an idea of what is the quality, intensity, meaning value, and extensity of the red star for these two persons. These attributes stem from the general psychological compartments -cognition, emotion and motivation -and they make operationalizing, measuring and comparing experiences easier. The same general psychological constructs should be able to use to assess different forms of new technology in order to understand UX. But if we do not know why and how they observe these celestial objects, we cannot understand their experiences, let alone measure them in a valid way. People do similar things for completely different reasons. 


\subsection{Psychology of User Experience}

Human experience is a very complex process. Perhaps, the most well known explanation about it is the notion used by William James: "the content of consciousness is experience" (James, 1890). In order to understand, how experience evolves in consciousness, relevant psychological constructs need to be defined and used, but in a suitable, simplified form. Firstly, we need to know, what are consciousness and awareness. In the introduction part of his book Optimal Experience - Psychological studies of flow in consciousness, Mihaly Csikzentmihalyi (Csikszentmihalyi \& Csikszentmihalyi, 1988) gives a general overview of the structure and functioning of the consciousness. Based on, for example, (Pope \& Singer, 1978) Csikzentmihalyi suggests that consciousness can be divided into three subsystems: 1) attention 2) awareness and 3) memory. Lots of environmental stimuli are perceived but only a minor proportion of this is interesting enough to draw our attention and to become a content of our consciousness. Most of our daily routines are experienced rather automatically or sub-consciously (Forlizzi \& Ford, 2000). Those perceptions that draw our attention enter the consciousness and become interpreted by the awareness. Awareness can be better understood by its three main processes or faculties originally proposed by Moses Mendelsshon in 1795, they are: understanding (cognition), feeling (affection) and will (conation) (Hilgard, 1980). Over decades this trilogy has been considered to concern human cognition, emotion and motivation (Mayer, 2001). Thus, we perceive and focus our attention to stimuli that motivate and interest us (James, 1890). The cause for the interest and motivation may originate from the environment (e.g., survival), but it is often our intrinsic needs that motivate our perceptual processes and focus of attention. Cognitively we recognize and relate these stimuli with each other and with our past experiences stored in our memory (Glenberg, 1997). Such an interpretation process is informational in nature, and it is enhanced by emotional labels that are attached to it (Lazarus, 1991a). Damasio (Damasio, 1994) describes the role of the somatic markers in the body as crucial in emotional labeling of our perceptions. He pointed out that our cognitive reasoning would be impaired without such bodily reference to a certain stimuli. These somatic markers stem from our bodies and they are felt as emotions and feelings in our awareness (Fig 1.).

When we understand our perceptual-attentional processes, cognitive reasoning, emotions, personal relevance, and past experiences related to a certain events and objects only then we can have an idea of the central experiential attributes involved in any human activity. Needless to say, this is a formidable task. However, we can begin our journey of discovery from events that have a clear beginning and an end, such as playing a video game (Dewey, 1934). Then we would need a psychological approach that provides us heuristics (Takatalo et al., 2007), within which we can evaluate different aspects of the experience; its content, intensity, meaning, value, quality, and extensity (James, 1890; Wundt, 1897). Being able to measure these attributes helps us to evaluate and rank anything that a person interacts with, weather it is a digital game or a cellular phone. The application of the presented psychological framework to such use cases is quite complicated and requires a 


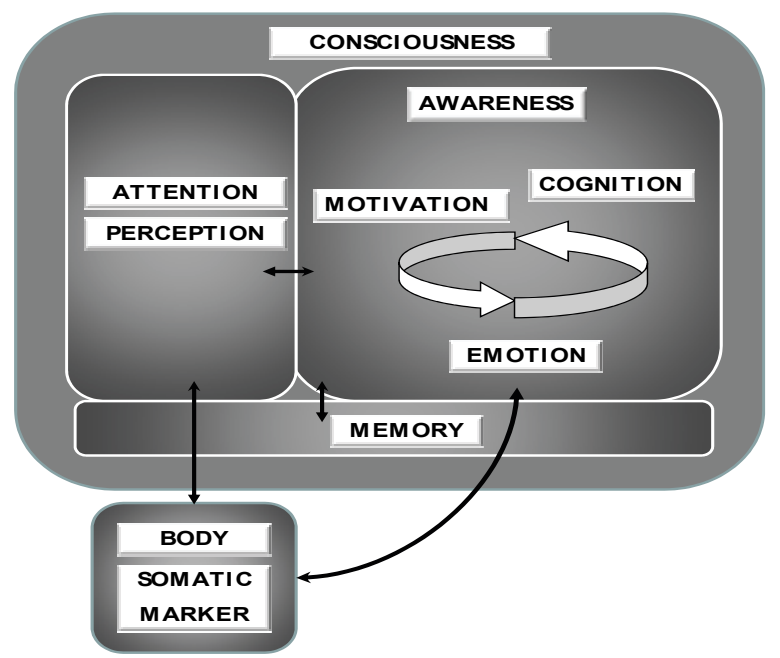

Fig. 1. The reciprocal relationship between body and mind in forming the experience

deep analysis of the used technologies, users and the contexts of use. In our red star example, for example, the experiences of two persons may vary greatly if one is a die-hard fan watching a football game in "Marakana" stadium, the home of the Red Star Belgrade and the other is an American anti-communist, who has lived through the cold war. By analyzing their cognitions, emotions and motivations quite different meaning and value is attached to the red star. There is no "pure" perception of a red star - or any other stimulus. Also the intensity and quality of an experience received may vary quite a lot. When we start analyzing such experiences that we receive from our environment, it becomes obvious that the mind is not composed of boxes that work as a simple linear system. Keeping in mind that these components are essential parts of the mind, we combine them into wider psychological concepts and frameworks so that we can try to utilize and even measure them in practice. This is what we have tried to do.

\subsection{Need \& Motivation, Adaptation and Appraisal}

Here we show how the above psychological components are likely to be connected in an experiential cycle. We use the constructs of need and motivation to refer to interests and curiosity that guide our attention and environmental perceptions. Next phase in this experiential cycle is denoted as adaptation. It means adaptation to, for example, a situation, environment or content and it is considered as one of the central functions of the consciousness (Angell, 1907). Consciousness has been considered to mediate between the needs of the complex being and the demands of the complex environment (James, 1890). In nature, the life has always been easier for those who have been able to adapt into the requirements of the environment. During the stage of adaptation, the environmental features become cognitively interpreted and referred to memory structures of the past 
experiences. Adaptation is closely related to the third stage - appraisal, which is an evaluation of the knowledge about the current situation of our personal goals and wellbeing in a particular environmental interaction. Because such knowledge is important and meaningful to us, emotions occur in relation to them (Lazarus, 1991a). In short, appraisal combines cognitive evaluation of the goal-directed interaction in an environment with emotions and feelings evoked by these interactions. In addition, appraisal has an impact on our motivation to either maintain or re-direct our ways of interacting. In this way the experiential cycle circles along the stages need \& motivation-adaptation-appraisal. But, there are abundant environmental objects (product, service, event, design, or system), subfeatures of them (e.g., cellular phones, software) and different ways and contexts of using them (communicating, taking photos, word processing, or playing games). All these contribute to UX by affecting the way this cycle is rolling. It is a complex and dynamic process.

In general, technologies are designed to bring added value to our lives and extend our capabilities. Ideally, it would be beneficial to fit variety of technologies into the UX framework such as experiential cycle. This would allow the measurement and understanding of how UX evolves in the human mind in general. Naturally, this would be limited to a very superficial level and when more accurate and practical measurement models are requested, a detailed analysis of the studied technologies, users and contexts is needed. Here we have embedded game software and cellular phone into the experiential cycle in order to demonstrate complex, but still understandable UX-related phenomena. We then continue to explain UX in games in more detail. Users in the experiential cycle example are restricted into experienced ones, who engage with a game or a phone on a daily basis and have already used them for a while. The use context is restricted to communication with a distant friend and a first person driving game played offline against the computer.

Need and motivation to use a phone to communicate with a distant friend stems from its capability to extend our natural resources and to provide a good set of options in order to become connected. Depending on the nature of the communication need and the nature of the friendship, either a phone call or SMS can be used, for example. Quite similarly, also games provide added value to our life. They enclose us into places, stories and activities that elicit rich experiences. The reason to initiate the use, the context of use and the way the phone is used or what game is played are all crucial factors that contribute to UX, and hence to the way it should be measured. They all have an impact on how we attend to and perceive the technology at hand. Need \& motivation are also strengthened by the ongoing perceptual process; the way technologies feel, look and sound have a psychological impact every time they are interacted with. Due to this whole process, the focus of the evolving UX shifts towards interpretation and adaptation.

Having the need to use the cellular phone the user needs to adapt to the user interface and to the possible options (call, sms) available. We could say that a good UX with a phone is offered by a technology that allows as good adaptation to the user's needs as possible. An optimal technology should become our natural extension that supports playful and 
enjoyable interaction with the environment. Also the game software attempts to support playful interaction between a user and a game environment. However, in a game the interaction (its goals) is created by the game itself and this is accepted by the user simply by selecting this specific game software. In addition to interactivity, a game creates an illusion of space in which the interaction takes place. In both our cases system features such as adjustability and personalization of the technology are likely to deepen the adaptation. Motivation and adaptation are also likely to go hand in hand; if we are very motivated to use something then the adaptation is more desired and requirements of the system can be even lower. This was quite typical in the use of the first computer games. Only now it is easy to see how primitive (but still adaptive) they were. On the other hand, motivation and a usable and fancy interface do not carry far without proper functionality and meaningful content. However, there are some differences in the way these two cases, phone and game, are appraised.

We evaluate the current situation of our personal goals and well-being based on the relevant outcomes of person-environment interactions. The goal of the phone use is to get connected with a friend. However, there are two different interactions going on that are appraised: physical interaction between a user and a phone as well as social interaction between a user and a friend. If there are, for example, challenges in the first interaction they are most often due to bad usability or technical problems. On the other hand, challenges in the other interaction are related to the content of the conversation. This makes it difficult to evaluate how technology alone actually affects UX. The critical issue then is the technology's ability to support the chosen way of communicating; does it make it better or worse, does it bring new dimensions to it such as anonymity. In the long run, issues such as the brand, social status, durability, and liability of a phone have their significant contributions to UX.

In our other case, a game is appraised based on its ability to provide experiences. Because games provide strong and real-like experiences by transporting the user psychologically away form the real world, the goals provided by the game become part of the users goal to go and experience what is afforded. Thus, the appraisals of the in-game interactions strongly affect UX in games. Also in playing games, clear technical challenges diminish the UX. On the other hand, in-game challenges are natural and important part of a good UX in games. In both our cases the appraisal of the situation is likely to lead to emotions, which again guide our motivation to play and use cellular phone again or search better ways to fulfil our needs to get experiences or communicate with a friend (Lazarus, 1991a).

We have shown that compressing general psychological components into larger concepts are useful in evaluating evolvement of UX in different kinds of technologies. When more detailed understanding of the UX is requested, more accurate measurements and methods are needed. We continue on analyzing UX in games in more detail.

\section{UX in Games}

Games are played to get experiences. The way to assess such experiential process may vary, 
but the selected framework and method should not disregard any part of the mind's trilogy. Analysis of this trilogy reveals the quality, intensity, meaning, value, and extensity of the experience.

Although games are studied in the field of HCI, there is a need for a systematic empirical analysis of the UX. Common to many game studies is that they consider UX in games as fun, which makes players enjoy playing and motivates them to keep on playing (Sweetser \& Wyeth, 2005). Challenge (goals and uncertainty), fantasy (emotions and metaphors) and curiosity (novelty and surprise) were probably the first empirically based guidelines to produce more interesting, enjoyable and satisfying computer systems, such as games (Malone, 1981). Since then numerous heuristics to design better games have been introduced (Desurvire et al., 2004). Indeed, such heuristics can be used to suggest, what to include into a game. However, to evaluate such a game a psychologically grounded approach to the problem is needed. Theoretical frameworks such as MDA (Mechanics, Dynamics, and Aesthetics) attempt to integrate game structure (e.g., mechanics) to experiential outcomes (Hunicke et al., 2004). But also they share the same problem with the heuristics; they are validated mostly by the professional game designers and developers (Barr et al., 2007). In order to empirically grasp the psychological core of UX, theoretical models are important starting points on which to lay ground for the study.

Fun is often considered as the main motivation to play, thus there are studies that concentrate on the sources of fun in gaming. For example, in an empirical study the motivation of the 30 players and 15 non-players to play or not to play digital games was studied (Lazzaro, 2004). The results indicated four major emotional motivations to play games. These "four keys" were challenges (overcoming obstacles), grab attention (curiosity, excitement, adventure), altered states (emotions and sensations) and other players (competition, co-operation with others). Similar uses of gratification dimensions were factor analytically extracted in a larger study $(n=550)$ (Sherry et al., 2006). When these two studies were compared, the latter one specified altered state to level of arousal, grab attention to fantasy and other players to two distinct dimensions of competition and social interaction. It also included one new dimension, that is, diversion from other things, such as studying. Larger empirical samples $(n=3200)$ have also been studied in order to understand player's motivations (Yee, 2005). Although these studies were conducted within a one genre (MMORPG), the results of the principal components analysis share similarities with the above cross-game studies. Concentrating on one genre enables a more accurate list of ingame challenges (e.g., advancement, competition). However, to uncover the general experiential laws in games, a cross-game sample and systematic psychological analysis of UX is needed.

Empirical studies in general can provide a reliable insight into the user's inner world. They should show how various experiential phenomena can be mapped, based on the empirical data. However, the above studies appear to fall short of identifying standard set of mental constructs and the way these jointly affect UX. A more dynamic and structural approach is adopted in the Microsoft Game Studios (Pagulayan et al., 2003). In these empirical, user- 
centered, studies the goal has been to find standard components to assess the formation of fun. These studies show that fun is likely to stem from various sources depending on the complex relationship between the game and the player. One of the key components of this approach is challenge, the level of which is evaluated with subjective methods.

The findings of the gaming studies can be generally summarized in terms of the following components of fun: Challenges (overcoming obstacles, clear goals), Emotions and internal sensations (arousal, enjoy, relax), Fantasy (adventure, escapism), Curiosity (discovery, attention, exploration, learning), Other players (social interaction, competition, cooperation) and Narrative (drama, role). In addition to these, wider concepts such as immersion (Brown \& Cairns, 2004; Davidson, 2003; McMahan, 2003; Sweetser \& Johnson, 2004), presence (McMahan, 2003; Nakatsu et al., 2005; Pinchbeck, 2005; Ryan et al., 2006; Takatalo et al., 2006b; Takatalo et al., 2004), flow (Nakatsu et al., 2005; Sweetser \& Wyeth, 2005; Takatalo et al., Submitted), involvement (Davidson, 2003; Takatalo et al., 2006b), engrossment and engagement (Brown \& Cairns, 2004) are often used to explain fun and UX in games. But, immersion, for example, is such a wide concept that it includes all the above experiential aspects. So, it would be more useful to measure its psychological components in order to recognize its basic elements. Because of this kind of psychological challenges in measuring UX, we have developed a Presence-involvement-Flow -Framework (PIFF2) that aims at measuring essential psychological components of UX in games. PIFF² can be seen as a game specified UX framework that is in accordance with the presented general psychological framework and the experiential cycle. It just goes deeper in order to provide a holistic understanding of the UX in digital games and explaining how UX gets its quality, intensity, meaning, value, and extensity.

\section{Presence, Involvement and Flow in Games}

\subsection{Involvement and Presence}

Issues related to need \& motivation and adaptation in our experiential cycle are dealt in PIFF $^{2}$ with more game-related concepts: involvement and presence. First of all, players must invest time, effort and attention into a game in order to get any relevant experience from it (Brown \& Cairns, 2004; Davidson, 2003). This can be measured with an involvement construct (Zaichkowsky, 1985), which is defined as a continuum of unobservable state of motivation, arousal or interest towards a particular situation or stimulus (Rothschild, 1984). The involvement construct and its two distinct but correlated dimensions importance and interest (McQuarrie \& Munson, 1992) together assess the psychological depth and quality of the player-game relationship. The psychological nature of importance is dominantly cognitive and it concerns the meaning and relevance of the stimulus, e.g., what matters to the player, whereas interest measures emotional and value-related valences, with response items such as "it was exciting" (Schiefele, 1991).

Presence has been studied in variety of media, for example, virtual environments, television, movies and digital games (Lombard \& Ditton, 1997). The existing studies indicate that the experienced presence can significantly vary with the technology used. Lombard and Ditton 
(Lombard \& Ditton, 1997) conceptualized the presence in mediated environments as a combination of physical and social presence. They differentiated three components in the physical presence: attention (psychological immersion), perceptual realness (naturalness) and spatial awareness (transportation). This threefold construct has also been confirmed in previous factor analytical studies (Lessiter et al., 2001; Schubert et al., 2001). In addition, the range and consistency of the physical interaction is considered an integral part of the sense of presence (Lombard \& Ditton, 1997). Some authors even see it as the only determinant of the presence experience (Zahorik \& Jenison, 1998). Thus it is also valuable and even necessary to be considered in interactive digital environments such as game worlds (Davidson, 2003; Sweetser \& Johnson, 2004).

The sense of presence is not related to physical aspects alone but to the social scope of the technology environment. This type of presence experience needs to be considered especially in mediated environment with social content. Such environments are likely to elicit the sense of social presence. In the Lombard and Ditton's (Lombard \& Ditton, 1997) explication, social presence was composed of social richness (intimacy-immediacy), social realism and co-presence (shared space). Social richness is "the extent to which a medium is perceived as sociable, warm, sensitive, personal or intimate" (Lombard \& Ditton, 1997). Social realism refers to the sense of similarity between real and game-world objects, people and events. In gaming the perceived drama and plot and engagement to own role in the storyline fit well in to this aspect of social presence. Co-presence is the feeling of being and acting there in a game-world together with other agents. Often such a social impact is strongly demonstrated in situations where participating agents have the same object of interest as the player has.

Together involvement and presence describe how players voluntarily form a relationship with a physical and social aspects of a digital game, that is, adapt to it (Takatalo et al., 2006b; Takatalo et al., 2006c). Taken together these two distinct dimensions form our adaptation measurement model. Psychologically, it describes the perceptual-attentive, motivational and cognitive aspects of the UX in games. In addition, arousal regulation is intimately linked with the human attentive system: high level of emotional arousal enables greater allocation of attentive resources into a particular event or stimuli (Kahneman, 1973). Together these psychological components describe the meaning and value as well as the intensity and extensity (i.e., voluminous or vastness, a spatial attribute) of the UX in games.

\subsection{Flow}

Appraisal part of the experiential cycle is approached with the theory of flow (Csikszentmihalyi, 1975). Csikszentmihalyi (Csikszentmihalyi, 1975) defines flow as a positive and enjoyable experience stemming from interesting activity that is considered worth doing for its own sake. In a state of such an optimal experience, individuals tend to be playful (cognitively spontaneous, inventive, and imaginative) (Ghani \& Deshpande, 1994; Novak et al., 2000; Webster \& Martocchio, 1992), self-consciousness is lost, action and awareness merge, and time passes more rapidly (Csikszentmihalyi, 1975; Csikszentmihalyi, 1990; Ghani \& Deshpande, 1994). In addition, concentration, clear goals, instant feedback, and a sense of control are considered to contribute to flow (Csikszentmihalyi, 1990). 
However, the right number and the relevance of flow factors are not clear (Finneran \& Zhang, 2002). For example, losing self-consciousness and the merging of action and awareness have been found to be difficult for respondents to recognize (Rettie, 2001). On the other hand, in almost every study related to flow, the two cognitive key antecedents evaluations of the challenges provided by the activity and the skills possessed by the respondents - are included.

Every time people engage in a meaningful activity, a mental process is activated where the evaluation of its challenges and the skills it requires occurs (Csikszentmihalyi, 1975). Different ratios between these two are likely to lead to different emotional outcomes. There are a few different flow-channel models that share this basic idea of having various emotions due to an evaluation process that concerns human-environmental interaction. For example, the eight-channel model (Massimini \& Carli, 1988) includes eight different emotional outcomes and two different cognitive evaluations. A positive state of flow evolves through a process in which both the skills and the challenges are evaluated as being high and in balance. Psychologically, the core idea of the flow theory (Csikszentmihalyi, 1975) is similar to cognitive theories of emotions (Ellsworth \& Smith, 1988; Frijda, 1987; Lazarus, 1991b). These theories suggest that cognitive interpretations and appraisals of events in the world are necessary parts of emotions. Some neuroscientific data seems to support these findings (Roseman \& Evdokas, 2004). There are various appraisal features and components, such as the effort anticipated in a situation, perceived obstacles, and the sense of control, all of which shape the emotions attached to these events (Ellsworth \& Smith, 1988).

Psychologically, the flow part of the PIFF² describes the cognition, emotion and feeling. Also memory and previous experiences have an affect on the cognitive appraisal process and the forming of emotions and feelings depicted here. The cognitive and emotional profiles provide by the flow model give insight to the both qualitative and intensity attributes of the experience and their cognitive predecessors. Combining adaptation and flow measurement models into one framework has a strong theoretical foundation. Together the two models give us a holistic profile of the content of the UX in games. These profiles are based on players' subjective interpretations of the game event, made within the pre-set psychological boundaries.

\subsection{PIFF $^{2}$ : Methodological Issues}

We emphasize the importance of evaluating the conscious top-down experiences. We have used subjective methods (e.g., interviews and questionnaires) that allow users reflect their own experiences. Such subjective analysis methods have a long tradition in the field of psychometrics and behavioral sciences to assess, for instance, attitudes, aptitudes, interests and personality. However, there has been a debate against the use of subjective methods in analyzing subjective experiences such as the sense of presence (Slater, 2004). Naturally, all methods have their pros and cons. Critics are appropriate towards questionnaires including question items with unfamiliar or many-faced constructs. Sometimes researcher may cut corners and develop single questions or simple scales to study multidimensional phenomenon such as presence. This is a major fault methodologically leading to unreliable 
scales (Cronbach, 1990) and poor construct validity of the measurement model. In our previous study we have shown what will happen if an oversimplified measure of presence is used to analyze difference between four different PC-games (Takatalo et al., 2006c). In our study the measured experience of presence digital games context included five dimensions. When these dimensions were grouped into one "meta-presence" dimension, all the games scored high in presence. As the games were studied with separate presence dimensions, clear differences between games were found. This example clearly demonstrated the multidimensionality of the presence construct. It also shows that presence is a latent psychological construct (Tarkkonen \& Vehkalahti, 2005) that cannot be directly reached. Compressing five distinct presence dimensions into one "meta-presence" dimension is analogous to the simple presence scale measuring only one aspect of presence. However, in digital games context the sense of being there is composed of sub-scales such as attention and role engagement (Takatalo et al., 2006b). An extra positive outcome of such an approach is that the participants of the studies have easier to understand what is meant by subjectively more observable components. Thus, the subjective phenomena become easier to assess.

To analyze complex issues such as UX in the field of HCI, any reasonable method should not be overlooked. When subjective methods are used, special care must be taken in considering both reliability and validity of the measurements. It is not enough to concentrate on the statistical side of the scale construction (how to measure) and ignore the theoretical issue of what is measured. If the scales are made up without any theoretical background, they can measure totally different things than they were supposed to do, despite the high levels of internal consistency of the scales (Slater, 2004). When human mind and subjective experiences are concerned, the scales measuring them should have some relationship to basic psychology otherwise the $\mathrm{H}$ - with all its history and theoretical developments in psychology - in HCI will forgotten. Similarly, if psycho-physiological methods (e.g., electromyography) are used without proper knowledge of human anatomy the results may be reliable but not valid in any way. For example, if electromyography (contraction of facial muscles) electrodes are attached to one of the thigh quadriceps before playing a game, a consistent and accurate response graph will be obtained but it has no relevant meaning. The above theoretical and methodological issues in mind we have collected empirical data on digital games context and statistically extracted measurement scales forming PIFF².

\section{The Data to Form Measurement Scales}

\subsection{Origin and Collection of the Dataset}

The data have been collected from both laboratory experiments and an Internet survey using the EVE-Experience Questionnaire (EVEQ-GP) (Takatalo, 2002; Takatalo et al., 2004). In the field of behavioral sciences the use of questionnaires has proven to be a valid way of assessing an extensive number of mental phenomena (Breakwell, 2006; Couper, 2000; Labaw, 1980; Rust \& Golombok, 1999). Both the paper and pencil and the online versions of the EVEQ-GP are composed of 180 items (1-7 Likert-scale and semantic differentials) 
measuring different experiential aspects obtained from being, performing and experiencing the game world. When the data was collected outside laboratory, the instructions for completing the EVEQ-GP encouraged participants to reflect on their subjective gaming experience of one particular gaming session that they have just finished. The instructions emphasized that the questionnaire was to be completed immediately after a gaming session. In the laboratory, the situation was straightforward as the players just described the game they had just played there. Thus, the gaming experience was operationalized as a situated experience stemming from one particular game. The method used enabled the player to report, within pre-set multidimensional boundaries, how it felt to interact with a specific digital game. Also included were 27 background questions.

An online version of the EVEQ-GP (VK2) was used to collect data from the Internet. Participants were asked to focus on one particular gaming session and fill in the questionnaire while keeping that session in mind. The instructions recommend filling in the questionnaire right after a playing session. The application development software used to create VK2 was Lotus Domino Designer 6.5. Domino Server ran on HP Proliant DL380. The questionnaire was online for one month on the home page of the Pelit [Games] magazine (www.pelit.fi). Pelit is a leading PC gaming magazine in Finland, with a circulation of approximately 38300 and registered online users approximately 27000 . During the first week VK2 was on the main page; for the remaining three weeks it was linked to a short news story, located in the news section. One month on the Internet resulted in 1912 properly filled-in questionnaires.

In addition, two distinct laboratory experiments were conducted. In the first, 240 university students (120 males, 120 females) played two different driving games with two different displays. In this experiment a $2 \times 2$ between subject-design was used. Each participant played for 40 minutes, after which they were asked to fill in the EVEQ-GP. In the second laboratory experiment, 30 university male students played Halo: Combat Evolved for two consecutive sessions. After the second session they filled in the EVEQ-GP. Results from these particular studies have been reported elsewhere (Takatalo et al., 2004).

\subsection{Description of the Dataset}

The data set consist of 2182 subjects (1972 males, 210 females), who filled in the questionnaire. The mean age of the respondents was 21.5 years $(\mathrm{SD}=6.0)$. The average time of playing was 127 minutes $(S D=111)$ and the average size of the display used was 19.2" $(\mathrm{SD}=4.4) .33 \%$ of the respondents played daily, $29.6 \%$ played at least every other day, and $24.5 \%$ played often but not as often as every other day.

Most of the games played (31.5\%) before the questionnaire was filled in were first-person shooters (FPS) either online $(15.0 \%)$ or offline $(16.5 \%)$. The second most popular genre (15.0\%) was massive multiplayer online role-playing games (MMORPG), and the third (13.1\%) was single role-playing games (RPG) (13.1\%). The most popular single game played was World of Warcraft $(n=265)$, which is a MMORPG. Altogether the data included approximately 320 different games, giving a broad scope to the psychology of digital games. 
Since Pelit magazine focuses on PC games, $85.2 \%$ of the games were played with a PC and $14.8 \%$ with a console.

\section{Measurement Scales}

The first version of the Presence-Involvement-Flow -framework (PIFF) was based on two, earlier collected and smaller datasets $(n=68 \& n=164)$. It included 23 scales measuring UX in games (Takatalo et al., 2004). After increasing the total sample size into 2182 participants, a factor analysis was conducted to the sample and 15 measurement scales composed of 139 individual variables were extracted (Takatalo et al., 2006b; Takatalo et al., Submitted). The resulting framework was thus named as PIFF$^{2}$ and it integrates two separate measurement models that assess presence and involvement (Takatalo et al., 2006b) as well as flow (Takatalo et al., Submitted). In addition to statistical psychometric validation the framework was also grounded to previous gaming studies, studies concerning both presence and flow and relevant psychological concepts.

\subsection{Involvement and Presence: Adaptation}

Of the total 180 EVEQ-GP items, 83 items were used to form an adaptation measurement model (Table 1.). A factor analysis (oblimin rotation) allowed us to extract 8 experiential, underlying dimensions. Together they describe how players voluntarily form a relationship with physical and social aspects of a digital game, that is, how they adapt themselves into a game-world (Takatalo et al., 2006b). The extracted scales have already been applied to analyze adaptation in different games (Takatalo et al., 2006c) and display types (Takatalo et al., 2006a). To learn more about the origin and previous use of the items the reader is referred to (Takatalo, 2002; Takatalo et al., 2004).

Of the 180 items, flow is measured with 56 items (Takatalo et al., Submitted). It is composed of two cognitive and five emotional dimensions. Together they depict both the cognitive evaluation and emotional consequences of a gaming session. They also show that different emotions result from a particular combination of cognitive evaluation and that clearly more complex feelings are related to gaming than just simply fun. Although the cognitive evaluation of the Interaction scale was extracted in the adaptation measurement model, it is dealt with two flow-related cognitive evaluations of competence and challenge in the results. All the statistical analysis was conducted with SPSS 13.0 statistical program.

\section{Case: Display and Gender in UX}

In this general case example we will show how PIFF2 works in practise. The aim is to show, how our multidimensional framework of UX in gaming is affected by the background of the user as well as the technological context, in this case, simply the form of the display. The results are shortly discussed and referred to experiential cycle as well as the experiential attributes. We do not go into technical or methodological details in this case. More trough analysis is presented elsewhere (Takatalo et al., 2006a). The case is restricted to one driving game (Need For Speed Underground), which was played for 40 minutes by 148 participants 
(75 women and 73 men) in a lab. After the gaming session, they filled in the EVEQ-GP questionnaire. The game was played with five different displays (CRT_1, CRT_2, stereo_1, stereo_2 and HMD) in a between-subjects design. The following background variables were used as covariates in an ANCOVA analysis in this example: experience with computers, skill in driving games, digital gaming frequency, driving gaming frequency, attitudes towards computers, attitudes towards driving games, average computer gaming time, and computer usages in a week.

Table 1. Name, number of items, Cronbach's alpha coefficient and short description of the scales forming the Presence-Involvement-Flow framework.

No gender differences were found in any adaptation scales. In flow scales, significant independent of covariates effects were evident in competence and challenge. Males

\begin{tabular}{|c|c|c|c|c|}
\hline Scales & $\begin{array}{c}\text { Name \& } \\
\text { nro.of items }\end{array}$ & & $\alpha$ & Description \\
\hline \multicolumn{5}{|c|}{ ADAPTATION } \\
\hline 1 & Role Engagement & 12 & .87 & Cap tivated and enclosed into the role and place provided by the story \\
\hline 2 & Attention & 12 & .89 & Time distortion. focus on the game world instead of the real world \\
\hline 3 & Interest & 6 & .80 & The game was interesting, ex citing as well as lively \\
\hline 4 & Importance & 8 & .90 & The meaning of the game, game was relevant, close, personal and sensitive \\
\hline 5 & Co-Presence & 14 & .89 & Feeling of sharing a place with others, being active in there \\
\hline 6 & Interaction & 9 & .74 & Speed, range, mapping, exploration, predictability of own actions \\
\hline 7 & Arousal & 5 & .64 & Active, stimulated vs. passive, unaroused \\
\hline 8 & Physical Presence & 17 & .88 & Feeling of being transported into a real, live and vivid place \\
\hline \multicolumn{5}{|l|}{ FLOW } \\
\hline 9 & Valence & 10 & .86 & Positive valence, happy, not bored or anxious \\
\hline 10 & Impressiveness & 9 & .75 & Amazed and impressed by the game-world, the game elicited real feelings \\
\hline 11 & Competence & 11 & .87 & Skill ed, competent, enjoying using the skills, clear goals \\
\hline 12 & Challenge & 5 & .69 & Game was ch allenging, game required the use of my abilities \\
\hline 13 & En joyment & 7 & .83 & Playing was pleas ant, enjoying and exciting, I'll recomend it to my friends \\
\hline 14 & Play fulness & 9 & .78 & E ase of d oing, crea tive, live and vivid, not un imagina tive \\
\hline 15 & Control & 5 & .71 & Feeling of being in control and in dependent \\
\hline
\end{tabular}

Table 1. Name, number of items, Cronbach's alpha coefficient and short description of the scales forming the Presence-Involvement-Flow framework ${ }^{2}$. 
evaluated their competences higher and females the challenges provided by the game higher. After controlling for the attitudes toward driving games and the duration of a typical gaming session, females considered gaming more playful. Females considered gaming also more enjoying, when both the attitudes towards new technology and towards driving games were controlled for. Also non-significant independent tendencies were found, males with equal previous experience with car games considered to be marginally more in control whereas females considered the game more meaningful and personally relevant (Fig. 2.).

To sum up, gender, independent from background of the users, makes participants evaluate themselves differently in the gaming situation. The difference in competence-challenge ratio indicates different cognitive abilities between genders. Fast paced, $1^{\text {st }}$ person driving game requires skills such as $3 \mathrm{D}$ rotation and field independent spatial perception, in which males have advantage (Sherry, 2004). Despite this, females with equal previous experience and attitudes had qualitatively richer UX than males. This shows the complex nature of the UX: being competent and in control is not always enough for a qualitatively rich UX. Personal relevance and meaning have also impact on the quality of UX. It shows that males tend to

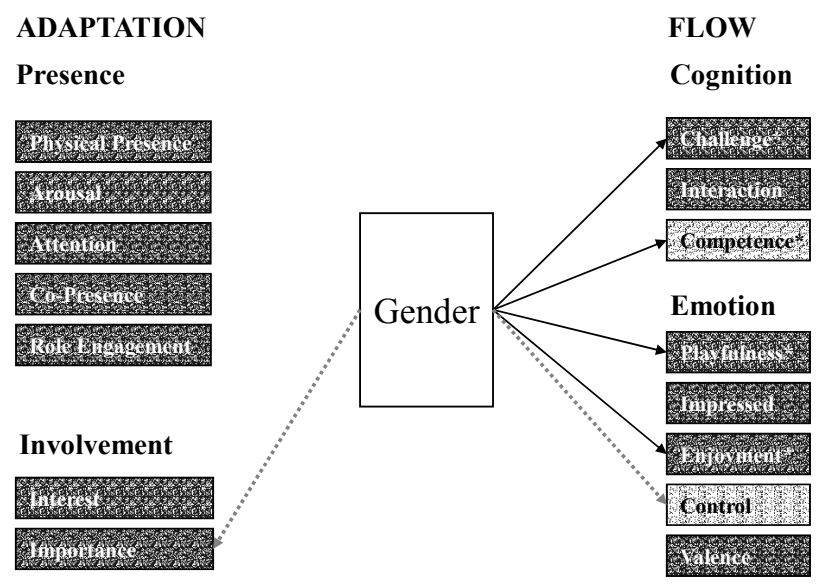

Fig. 2. Independent effects of on the PIFF² factors. Lighter boxes indicate higher scores for men, darker boxes higher scores for women. * indicates $\mathrm{p}<0.05$, dashed lines indicate marginally significant effects.

evaluate games more cognitively and competitively. They also seem to feel that they are more competent, whereas females seem to attach emotional values more easily to the games. The type of the display did not affect the appraisal of the game event. The display type affected only on adaptation, especially on three out of five presence dimensions. Figure 3. presents the independent effects of the display type to the PIFF2 factors, after controlling for gender and the other background factors. Highest in Physical presence and Role 


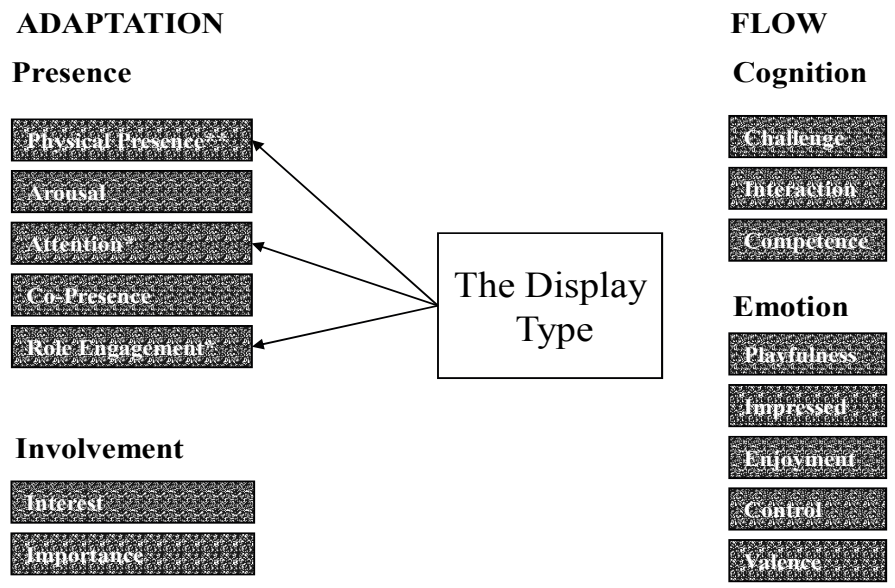

Fig. 3. Independent effects of on the display type on PIFF² factors. ** indicates $p<0.01$ and * indicates $\mathrm{p}<0.05$

Engagement were stereo_1 and HMD conditions. HMD was also highest in Attention. These results indicate how display parameters shape our adaptation by affecting the sense of being in the game world. These changes in presence affect the extensity (e.g., voluminous) and intensity of the UX. Taken these two simple results together, we have demonstrated how to make UX in games measurable. With PIFF2 analysis we have disclosed two factors that affect different parts of the experiential framework, and thus different experiential attributes. Linking PIFF2 factors with game characters, such as mechanics and dynamics will tell game designers how a particular game feature and any change of it will contribute on the UX in games in any given user groups.

\section{Conclusion}

In the near future, the field of UX research will become one of the core fields of the psychological science. This will happen when the field adopts systematic and methodologically solid approaches. At the moment, the drivers for the interest in, e.g., game research are both technological and business related. The aim of this chapter is to introduce, how to approach UX in a psychologically founded way. We have presented general mental components that can be used to assess and evaluate any kinds of human experiences. Then we have formed an experiential cycle including higher level constructs of need \& motivation, adaptation and appraisal to show how psychology can be used to evaluate UX in cellular phone and in digital games. Emphasis is on the understanding of what is measured and how. Experiential attributes are presented that can be regarded as measurement goals. More specific way to analyze gaming experience is then presented in 
our third framework, PIFF2. The theoretical and methodological background of the PIFF² is explained and concrete example of it presented. In an empirical case study, it was showed that the display type had an effect on the adaptation, extensity and intensity of the UX, whereas gender had more effect on appraisal, quality and meaning of the experience.

Although gaming is getting more and more attention among the researchers, there are still only few attempts to study UX in games holistically. Although holistic approach is more demanding compare to focusing on one part of the UX, it enables evaluating complex mental relationships. Considering rich top-down processes in gaming will increase the understanding of the nature of today's games, development of better UX in new games, and future interactive interfaces that adapt users to whatever interactions. In addition, today's audio-visually rich and highly interactive games provide magnificent platforms to study human experiences. Increasing understanding about our mental processes will increase understanding of the $\mathrm{H}$ in $\mathrm{HCI}$ and eventually human life more generally.

\section{References}

Angell, J. R. (1907). The province of functional psychology. Psychological Review, 14, 2, 61-91, 0033-295X

Barr, P., Noble, J. \& Biddle, R. (2007). Video game values: Human-computer interaction and games. Interacting with Computers, 19, 2, 180-195,

Breakwell, G. M. (2006). Research Methods in Psychology, Sage Publications

Brown, E. \& Cairns, P. (2004). A grounded investigation of game immersion, Proceedings of CHI2004, pp. 1297-1300, ACM

Couper, M. (2000). Web surveys: A review of issues and approaches. Public Opinion Quarterly, 64, 4, 464-494, 0033-362X

Cronbach, L. J. (1990). Essentials of Psychological Testing, HarperCollins, New York

Csikszentmihalyi, M. (1975). Beyond Boredom and Anxiety, Jossey-Bass Publishers, San Francisco

Csikszentmihalyi, M. (1990). Flow: The Psychology of Optimal Experience, Harper \& Row, New York

Csikszentmihalyi, M. \& Csikszentmihalyi, I. S. (Ed). (1988). Optimal experience: Psychological studies of flow in consciousness, Cambridge University Press

Damasio, A. R. (1994). Descarte's Error: Emotion, Reason, and the Human Brain, Grosset/Putnam, New York, NY

Davidson, D. (2003). Interactivity in ico: Initial involvement, immersion, investment. Proceedings of the Second International Conference on Entertainment Computing, 1-21

Desurvire, H., Caplan, M. \& Toth, J. A. (2004). Using heuristics to evaluate the playability of games, Proceedings of CHI 2004, pp. 1509-1512, ACM Press, New York, NY, USA

Dewey, J. (1934). Art as Experience, Capricorn Books, New York

Ellsworth, P. C. \& Smith, C. A. (1988). From appraisal to emotion: Differences among unpleasant feelings. Motivation and Emotion, 12, 3, 271-302

Fabricatore, C., Nussbaum, M. \& Rosas, R. (2002). Playability in action videogames: A qualitative design model. Human-Computer Interaction, 17, 4, 311-368 
Finneran, C. M. \& Zhang, P. (2002). The challenges of studying flow within a computermediated environment, Proceedings of Eighth American Conference in Information Systems, pp. 1047-1054, Dallas, TX

Forlizzi, J. \& Ford, S. (2000). The building blocks of experience: An early framework for interaction designers, Proceedings of in Proc. DIS-2000, pp. 419-423, ACM Press New York, NY, USA

Frijda, N. H. (1987). The Emotions, Cambridge University Press, Cambridge

Ghani, J. A. \& Deshpande, S. P. (1994). Task characteristics and the experience of optimal flow in human-computer interaction. The Journal of Psychology, 128, 4, 381-391

Glenberg, A. M. (1997). What memory is for. Behavioral and Brain Sciences, 20, 1-19

Hassenzahl, M. \& Tractinsky, N. (2006). User experience-a research agenda. Behaviour $\mathcal{E}$ Information Technology, 25, 2, 91-97

Hilgard, E. R. (1980). The trilogy of mind: Cognition, affection, and conation. Journal of the History of the Behavioral Sciences, 16, 2, 107-117, 0022-5061

Hunicke, R., LeBlanc, M. \& Zubek, R. (2004). MDA: A formal approach to game design and game research, Proceedings of AAAI Workshop on Challenges in Game AI, p. 4

James, W. (1890). The Principles of Psychology, H. Holt and company

Kahneman, D. (1973). Attention and Effort, Prentice-Hall, Englewood Cliffs, NJ

Labaw, P. J. (1980). Advanced Questionnaire Design, Abt Books

Lazarus, R. S. (1991a). Cognition and motivation in emotion. The American Psychologist, 46, 4, 352-367, 0003-066X

Lazarus, R. S. (1991b). Progress on a cognitive-motivational-relational theory of emotion. The American Psychologist, 46, 8, 819-834, 0003-066X

Lazzaro, N. (2004). Why we play games: Four keys to more emotion without story. Retrieved November, 2007, from

http://www.xeodesign.com/whyweplaygames/xeodesign_whyweplaygames.pdf

Lessiter, J., Freeman, J., Keogh, E. \& Davidoff, J. (2001). A cross-media presence questionnaire: The ITC-sense of presence inventory. Presence: Teleoperators $\mathcal{E}$ Virtual Environments, 10, 3, 282-297, 10547460

Lombard, M. \& Ditton, T. (1997). At the heart of it all: The concept of presence. Journal of Computer-Mediated Communication, 3, 2, 20

Malone, T. W. (1981). Toward a theory of intrinsically motivating instruction. Cognitive Science, 4, 13, 333-369

Massimini, F. \& Carli, M. (1988). The systematic assessement of flow in daily experience. In Optimal experience: Psychological studies of flow in consciousness, I. Csikszentmihalyi, \& M. Csikszentmihalyi (Ed.), 266-287, Cambridge: Cambridge University Press

Mayer, J. D. (2001). Primary divisions of personality and their scientific contributions: From the trilogy-of-mind to the systems set. Journal for the Theory of Social Behaviour, 31, 4, 449-477

McMahan, A. (2003). Immersion, engagement and presence: A method for analyzing 3-D video games. In The video game theory reader, M. J. P. Wolf, \& B. Perron (Ed.), 67-86, New York: Routledge

McQuarrie, E. F. \& Munson, J. M. (1992). A revised product involvement inventory: Improved usability and validity. Advances in Consumer Research, 19, 108-115 
Nakatsu, R., Rauterberg, M. \& Vorderer, P. (2005). A new framework for entertainment computing: From passive to active experience, Proceedings of ICEC 2005, pp. 1-12, Kwansei Gakuin University, Kobe Sanda Campus, Sanda, Japan, IFIP

Novak, T. P., Hoffman, D. L. \& Yung, Y. F. (2000). Measuring the customer experience in online environments: A structural modeling approach. Marketing Science, 19, 1, 2242 ,

Pagulayan, R. J., Keeker, K., Wixon, D., Romero, R. \& Fuller, T. (2003). User-centered design in games. In Handbook for human-computer interaction in interactive systems, J. Jacko, \& A. Sears (Ed.), 883-906, Mahwah, NJ: Lawrence Erlbaum Associates Inc.

Pinchbeck, D. (2005). Is presence a relevant or useful construct in designing game environments? Proceedings of Computer Game Design and Technology, Liverpool, UK. 8-9th November 2005

Pope, K. S. \& Singer, J. L. (1978). The Stream of Consciousness: Scientific Investigations into the Flow of Human Experience, New York: Plenum

Rettie, R. (2001). An exploration of flow during internet use. Internet Research: Electronic Networking Applications and Policy, 11, 2, 103-113

Roseman, I. J. \& Evdokas, A. (2004). Appraisals cause experienced emotions: Experimental evidence. Cognition \& Emotion, 18, 1, 1-28

Rothschild, M. L. (1984). Perspectives on involvement: Current problems and future directions. Advances in Consumer Research, 11, 216-217

Rust, J. \& Golombok, S. (1999). Modern Psychometrics: The Science of Psychological Assessment, Routledge

Ryan, R., Rigby, C. \& Przybylski, A. (2006). The motivational pull of video games: A selfdetermination theory approach. Motivation \& Emotion, 30, 344-360, 01467239

Schiefele, U. (1991). Interest, learning, and motivation. Educational Psychologist, 26, 3, 299-323

Schubert, T., Friedmann, F. \& Regenbrecht, H. (2001). The experience of presence: Factor analytic insights. Presence: Teleoperators \& Virtual Environments, 10, 3, 266-281, 10547460

Sherry, J. L. (2004). Flow and media enjoyment. Communication Theory, 14, 4, 328-347

Sherry, J. L., Lucas, K., Greenberg, B. S. \& Lachlan, K. (2006). Video game uses and gratifications as predictors of use and game preference. In Playing video games: Motives, responses, and consequences, P. Vorderer, \& J. Bryant (Ed., 213-224, Mahawa, New Jersey: Lawrence Erlbaum Associates

Slater, M. (2004). How colorful was your day? why questionnaires cannot assess presence in virtual environments. Presence: Teleoperators \& Virtual Environments, 13, 4, 484-493, 1054-7460

Sweetser, P. \& Johnson, D. (2004). Player-centred game environments: Assessing player opinions, experiences and issues, Proceedings of ICEC 2004, pp. 321-332, Springer

Sweetser, P. \& Wyeth, P. (2005). GameFlow: A model for evaluating player enjoyment in games. Computers in Entertainment, 3, 3, Article 3a

Takatalo, J., Häkkinen, J., Särkelä, H., Komulainen, J. \& Nyman, G. (2006b). Involvement and presence in digital gaming, Proceedings of NordiCHI 2006, pp. 393-396, ACM Press, Norway

Takatalo, J. (2002). Presence and flow in virtual environments: An explorative study. Master's thesis, University of Helsinki. 
Takatalo, J., Häkkinen, J., Kaistinen, J., Komulainen, J., Särkelä, H. \& Nyman, G. (2006c). Adaptation into a game: Involvement and presence in four different PC-games, Proceedings of FuturePlay 2006, London, Ontario, Canada, 10 - 12 October 2006

Takatalo, J., Häkkinen, J., Kaistinen, J. \& Nyman, G. (2007). Measuring user experience in digital gaming: Theoretical and methodological issues, Proceedings of ISET/SPIE Symposium on Electronic Imaging, pp. 1-13, San Jose, California, USA, IS\&T/SPIE

Takatalo, J., Häkkinen, J., Komulainen, J., Särkelä, H. \& Nyman, G. (2006a). The impact of the display type and content to a game adaptation, Proceedings of MobileHCI 06, pp. 17-20, Espoo, Finland, 12 - 15 September 2006, ACM Press New York, NY, USA

Takatalo, J., Häkkinen, J., Lehtonen, M., Komulainen, J., Kaistinen, J. \& Nyman, G. (Submitted). Quality of the user experience in digital gaming

Takatalo, J., Häkkinen, J., Särkelä, H., Komulainen, J. \& Nyman, G. (2004). The experiential dimensions of two different digital games, Proceedings of PRESENCE 2004, pp. 274278, Valencia, Spain, October 12-15, UPV

Tarkkonen, L. \& Vehkalahti, K. (2005). Measurement errors in multivariate measurement scales. Journal of Multivariate Analysis, 96, 1, 172-189

Webster, J. \& Martocchio, J. J. (1992). Microcomputer playfulness: Development of a measure with workplace implications. MIS Quarterly, 16, 2, 201-226

Wundt, W. M. (C.H. Judd, trans), (1897). Outlines of Psychology, Retrieved April, 2002 from http://psychclassics.yorku.ca/Wundt/Outlines/

Yee, N. (2005). A model of player motivations. Retrieved January, 2008, from http://www.nickyee.com/daedalus

Zahorik, P. \& Jenison, R. L. (1998). Presence as being-in-the-world. Presence: Teleoperators $\mathcal{E}$ Virtual Environments, 7, 1, 78-89, 1054-7460

Zaichkowsky, J. L. (1985). Measuring the involvement construct. Journal of Consumer Research, 12, 3, 341-52, 00935301 


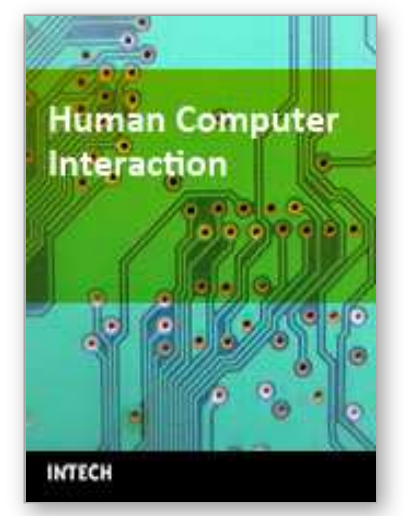

\author{
Human Computer Interaction \\ Edited by loannis Pavlidis
}

ISBN 978-953-7619-19-0

Hard cover, 522 pages

Publisher InTech

Published online 01, October, 2008

Published in print edition October, 2008

This book includes 23 chapters introducing basic research, advanced developments and applications. The book covers topics such us modeling and practical realization of robotic control for different applications, researching of the problems of stability and robustness, automation in algorithm and program developments with application in speech signal processing and linguistic research, system's applied control, computations, and control theory application in mechanics and electronics.

\title{
How to reference
}

In order to correctly reference this scholarly work, feel free to copy and paste the following:

Jari Takatalo, Jukka Hakkinen, Jyrki Kaistinen and Gote Nyman (2008). User Experience in Digital Games, Human Computer Interaction, Ioannis Pavlidis (Ed.), ISBN: 978-953-7619-19-0, InTech, Available from: http://www.intechopen.com/books/human_computer_interaction/user_experience_in_digital_games

\section{INTECH}

open science | open minds

\author{
InTech Europe \\ University Campus STeP Ri \\ Slavka Krautzeka 83/A \\ 51000 Rijeka, Croatia \\ Phone: +385 (51) 770447 \\ Fax: +385 (51) 686166 \\ www.intechopen.com
}

\author{
InTech China \\ Unit 405, Office Block, Hotel Equatorial Shanghai \\ No.65, Yan An Road (West), Shanghai, 200040, China \\ 中国上海市延安西路65号上海国际贵都大饭店办公楼 405 单元 \\ Phone: +86-21-62489820 \\ Fax: $+86-21-62489821$
}


(C) 2008 The Author(s). Licensee IntechOpen. This chapter is distributed under the terms of the Creative Commons Attribution-NonCommercialShareAlike-3.0 License, which permits use, distribution and reproduction for non-commercial purposes, provided the original is properly cited and derivative works building on this content are distributed under the same license. 